\title{
TIPOLOGIA DE CUIDADOS DE ENFERMAGEM SEGUNDO CLIENTES HOSPIT ALIZAD OS: encontro das dimensões técnico-científica e expressiva ${ }^{a}$
}

\author{
Paula A Ivarenga de F igueiredo M ART IN S ${ }^{b}$, D enise da Conceição SI LVAc, N eide A parecida T itonelli A LVI M d
}

\section{RESUMO}

Pesquisa qualitativo-descritiva, realizada em um hospital universitário do Rio de Janeiro, entre agosto de 2007 a dezembro de 2008. 0 bjetivou-se descrever os cuidados de enfer magem, caracterizando-os a partir das concepções de 26 clientes hospitalizados, sujeitos da pesquisa. Conjugou-se a técnica de criatividade e sensibilidade "A Imanaque" com a entrevista na produção de dados, seguida de análise de conteúdo temática da qual emergiu a categoria "Dimensões do cuidado de enfermagem na ótica dos sujeitos: técnico-científica e expressiva". Os resultados apontaram que estas dimensões devem se manifestar de forma articulada, sendo o cuidado concebido como integral e construído na relação com o outro. Os sujeitos valorizam e defendem a aliança entre tais dimensões, e esperam que a enfer meira possa integ rá-las nas ações de cuidado. 0 conhecimento acerca das concepções de clientes sobre os cuidados no hospital col abora na promoção de ambiente que favoreça sua restauração atr avés da efetividade do cuidado, gerada nessa relação.

D escritores: Cuidados de enfermagem. Assistência hospitalar. Humanização da assistência.

\section{RESUMEN}

E sta investigación cualitativa y descriptiva objetivó describir los cuidados de enfermería caracterizados a partir de concepciones de 26 dientes hospitalizados. F ue realizada en un hospital universitario de R io deJ aneiro, B rasil, entreagosto de 2007 y diciembre de 2008 . L a técnica de creatividad y sensibilidad "A I manaque" y entrevista fueron utilizadas para producción delos datos, los cuales fueron analizados por análisis de contenido temático. L a categoría "D imensiones del cuidado de enfermería bajo la óptica de los sujetos: técni co-científica y expresiva". L os resul tados mostraron que estas dimensi ones deben manifestarse de forma coordinada, con cuidado integral y construido en la relación con el otro. $L$ os sujetos val orizan y defienden la alianza entretales dimensiones, y esperan quela enfermera pueda integrarlas en las acciones de cuidado. Conocer las concepciones de clientes sobre los cuidados en el hospital colabora para promover un ambiente que favorezca su restauración a través de la efectividad del cuidado.

Descriptores: A tención de enfermería. A tención hospitalaria. H umanización de la atención.

T ítulo: T ipología de la atención de enfermería según clientes hospitalizados: encuentro de las dimensiones técni co-científica y expresiva.

\section{ABST RACT}

This qualitative descriptive study was carried out in a university hospital in R io de J aneiro, B razil, from A ugust, 2007 to D ecember, 2008. N ursing care was described and characterized based on the perceptions of 26 hospitalized patients. D ata collection was carried out through interview s and the "A Imanac" creative and sensitivity technique, follow ed by thematic content analysis from which the following category emerged: "N ursing care dimensions from the subjects' per spectives: scientific- technical and expressive". T he results show that these dimensions should be manifested in a coordinated way and integral care should be designed and constructed in the relationship with the other. The participants value and defend an alliance between these dimensions and expect nurses to integrate them into care actions. Know ledgeabout the patients' perceptions concer ning hospital care collaborates to thepromotion of theenvironment and favors its restoration through effective care generated in this relationship.

Descriptors: $\mathrm{N}$ ursing care $\mathrm{H}$ ospital care $\mathrm{H}$ umanization of assistance

T itle: T ypology of nursing care according to hospitalized clients: scientific-technical and expressive dimensions.

\footnotetext{
a Excerto do relatório final de Iniciação Científica e T rabalho de Conclusão do Curso de Enfermagem apresentado em 2008 à E scola de Enfermagem Anna Nery (EEAN) da U niversidade Federal do Rio de Janeiro (U FRJ), Rio de Janeiro, Brasil.

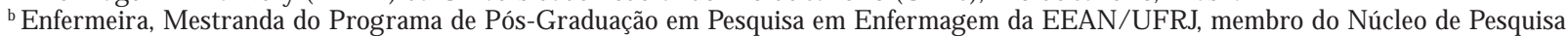
de $\mathrm{F}$ undamentos do Cuidado de Enfermagem (N uclearte), Rio de Janeiro, Brasil.

cM estre em Enfermagem pela EEAN/UFRJ, membro do Nuclearte, Rio de Janeiro, Brasil.

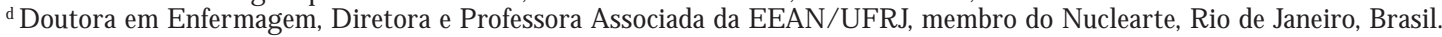




\section{INT RODUÇÃO}

0 cuidado éa essência da enfer magem, sendo característica fundamental à preservação da dignidade humana. 0 cuidado transpessoal manifesta-se no encontro das pessoas que estão envolvidas no ato de cuidar, ou seja, na reciprocidade entre a enfermeira e o cliente que dele resulta. Assim, está relacionado com a inter ação entre seres humanos através da intersubjetividade, permitindo um encontro real e autêntico entre quem cuida e é cuidado, transcendendo o mundo meramente físico e material, fazendo contato com o emocional e o subjetivo da pessoa. D aí o entendimento de que o cuidado, além de relacional, uma vez que envolve o encontro pessoa-pessoa, é também singular, pois se constrói tendo em vista o al cance das necessidades e desejos do cliente ${ }^{(1)}$. Princípios próprios da relação humana, como a compaixão, a expressão de afeto, a atenção, o zelo, a demonstração de respeito e a tolerância, qualificam o cuidado e, junto com 0 aporte técnico e tecnológico necessários ao atendimento do cliente, torna o diferencial entre este e 0 descuidado.

Qualquer pessoa que passa por um processo de hospitalização vivencia situação estressante e muitas vezes de sofrimento. Por um lado, 0 acelerado avanço técnico-científico no contexto da saúde tem resultado em alguns momentos em uma vaIorização excessiva desses aspectos em detrimento do respeito e de outras questões que permeiam as relações humanas. Por outro lado, têm-se as limitações impostas pelas características do ambiente hospitalar como ambiente impessoal e frio, local de tristeza, dor e sofrimento, associados à ideologia que prima pela manutenção da hegemonia capitalista e do modelo biomédico nesse espaço.

N ão obstante a esses obstáculos, pensamos ser possível prestar um cuidado humanizado no ambiente hospitalar, desde que concebamos o cliente como um ser pleno e total, dotado de características bio-psico-socio-espirituais únicas e indissociáveis. Para isso, é preciso respeitar a condição de sujeito do cliente, por sua vez, possuidor de crenças, valores, atitudes e comportamentos que marcam sua condição de ser ao mesmo tempo único e social. E ste aspecto revela a impor tância do estudo sobre os cuidados de enfermagem na concepção de clientes hospitalizados, sendo este o objeto do presente estudo, excerto do relatório final de I niciação Científica e T rabal ho de Conclusão de Curso(2).
0 objetivo foi descrever os cuidados de enfermagem na ótica de clientes hospitalizados, caracterizando-os a partir das concepções dos mesmos.

A pesquisa fundamenta-se na concepção de cuidado humano, segundo a qual este se compõe de tentativas intersubjetivas e transpessoais para proteger, melhorar e preservar a humanidade auxiliando uma pessoa a encontrar sentido na doença, sofrimento, dor e existência, e para ajudar 0 outro a alcançar autoconhecimento, autocontrole e autocura. A lém deste conceito, o estudo ancorase na classificação de cuidados técnico-procedimentais e expressivos ${ }^{(1)}$.

\section{MÉT ODO}

Pesquisa qualitativa-descritiva, realizada em um hospital universitário local izado na cidade do Rio de Janeiro. 0 lócus do estudo foram as unidades de inter nação de clínica médica, nefrologia e ortopedia. Os sujeitos constituíram-se de 26 clientes hospitalizados.

$\mathrm{E} \mathrm{m}$ atendimento ao disposto na Resolução 196/ 96 do Consel ho N acional de Saúde(3), a pesquisa teve seu projeto aprovado pelo Comitê de É tica em Pesquisa da instituição que serviu de cenário do estudo, protocolo n 269/06. A pós devidamente esclarecidos sobre os seus objetivos e sua forma de participação nela, os sujeitos assinaram o Termo de Consentimento L ivre e E sclarecido, tendo sido identificados com a letra alfabética C (cliente), seguida da ordem da geração dos dados: C1 a C26. As pesquisadoras foram identificadas com a letra P.

U tilizamos a triangulação de técnicas, conjugando a técnica de criatividade e sensibilidade (T CS) "A Imanaque" com a entrevista semi-estruturada. Esta técnica consiste na expressão da subjetividade a partir da introspecção que o recorte e colagem de gravuras de diversas naturezas proporcionam aos sujeitos da pesquisa. N o uso da T CS os sujeitos realizam produções artísticas que são norteadas pela temática central de discussão, neste estudo, versou sobre cuidados de enfer magem no hospital.

O local de produção de dados foi o próprio cenário da pesquisa. A entrevista ocorrida no entremeio do diálogo existente durante o desenvolvimento do Almanaque, direcionada também pela temática central, teve como perguntas geradoras: que cuidados de enfermagem são desenvolvidos 
com o (a) senhor (a)? 0 que o (a) senhor (a) pensa a respeito desses cuidados?

Os relatos dos sujeitos foram gravados em meio digital, após autorização dos mesmos, sendo transcritos na íntegra. A partir dos relatórios gerados com os resultados da implementação das técnicas, os dados foram analisados de acordo com a proposta de análise de conteúdo temática ${ }^{(4)}$. Empregou-se o critério de categorização temático na organização das idéias, fornecendo uma representação simpl ificada dos dados brutos obtidos em ambas as técnicas. Com tal objetivo utilizou-se a técnica de leitura flutuante para apreensão das idéias principais dos discursos dos sujeitos, sendo essas idéias agrupadas a partir de suas características comuns em unidades de registro, transformando os dados brutos em unidades de análise.

D este processo de categorização temática, emergiu a categoria "Dimensões do cuidado de enfermagem na ótica dos sujeitos", e as subcategorias "D imensão técnico-científica do cuidado de enfermagem" e "D imensão expressiva do cuidado de enfermagem".

\section{RESULTADOS E DISCUSSÃO}

\section{D imensões do cuidado de enfermagem na ótica dos sujeitos}

Os cuidados de enfermagem caracterizados como instrumentais englobam todos aqueles que atendem às necessidades biofísicas do cliente, como a higiene e a terapêutica medicamentosa. Os cuidados expressivos inserem o aspecto psicossocial na relação de cuidado e inclui a dimensão do afeto ao cuidar, garantindo, deste modo, o seu caráter humanístico(1).

Vale ressaltar que, as concepções de cuidado dos sujeitos ratificaram os pressupostos teóricos da pesquisa ${ }^{(1)}$ ao destacarem que as dimensões instrumentais e expressivas devem convergir nas ações do cuidado, ou seja, concebendo o cuidado como integral e construído na relação com o outro - o cliente, logo, del e dependendo o sucesso da ação do enfermeiro. Essas dimensões devem estar articuladas e expressas no cuidado de maneira interdependente, ambas norteadas por princípios éticos de responsabilidade, profissionalismo, zelo e respeito para com o cliente cuidado. Os sujeitos conceberam esses princípios como fundamentais para a realização de qual quer cuidado, tendo em vis- ta, principalmente, que estamos "lidando com vidas":

[ ...] T em que ter muita responsabilidade no que está fazendo! E stá lidando com vidas! (C19).

[ ...] E ntão primeiramente, ela deve gostar do que vai fazer! D eve amar àquela profissão! Porque vai lidar com vida, com ser humano! E ntão tem queter respeito! (C7).

Vale dizer que, embora entendendo as dimensões do cuidado de enfer magem, como convergentes e integradas, para efeito didático-ilustrativo, essas dimensões são apresentadas separadamente, de acordo com as suas características.

\section{D imensão técnico-científica do cuidado de enfermagem}

A o fal arem sobre os cuidados de enfer magem, associando a produção artística que desenvolveram junto às entrevistas, os clientes os conceberam como cuidados que requerem preparo e conhecimento científico de quem os executa de modo a embasar suas ações. Suas fal as remeter am à necessidade de o profissional ter conhecimento científico; manter-se atualizado; e ter agilidade e destreza de modo a adquirir segurança no fazer:

É ! P ra lidar com os clientes! Conhecimento para poder cuidar! [ ...] É ... P orquese a enfermeira não tiver conhecimento de nada, 0 que ela vai fazer? $\mathrm{N}$ ão vai saber cuidar... (C8).

[ ...] Conhecimento que elas têm na matéria, que ela passa! A segurança na matéria! 0 trabalho que elas fazem é com segurança! N ão ficam na incerteza do que vai fazer... N ão! São seguras no que estão fazendo! [ ...] (C2).

A fala de C8 destaca a necessidade de enfermeira embasar suas ações no conhecimento científico e de manter-se atual izada, de modo a cuidar com competência. É oportuno consider ar que, além do conhecimento científico há outros atributos inerentes à pessoa que cuida que podem assegurar uma prática de cuidar competente ${ }^{(5)}$. Compartilhamos do entendimento de que o conhecimento advindo da ciência é uma ferramenta importante na construção do cuidado, contudo, há outros el ementos que configuram o perfil do indivíduo competente, 
como a capacidade para inovar e criar associada a outras habilidades cognitivas e psicoafetivas. 0 discurso de C2 vai al ém ao referir que o conhecimento científico colabora com a aquisição de segurança no fazer, permitindo maior agilidade e destreza na execução do cuidado.

Cuidados de higiene, conforto e nutrição emergiram como fundamentais para os sujeitos. A judar no banho de asper são ou dar o banho no leito, trocar a fralda, escovar os dentes, cortar as unhas efazer a barba contribuem com a promoção do conforto por eles desejado, tendo em conta que conforto "[ ...] éuma experiência pessoal subjetiva que inclui sensações de mel hora, segurança/ proteção, cuidado, comodidade, liberdade e integração que ocorre quando não existe ameaça imediata à vida e à integridade do ser e quando a pessoa experiencia cuidado (próprio ou profissional) que resulta em restabelecimento das suas forças e poder pessoal possibilitando-Ihe enfrentar as situações de saúdedoença visando viver mais saudável"(6).

Ao referirem os cuidados quanto à al imentação, chamaram à atenção al guns el ementos essenciais que os qualificam, como a sensibilidade de compreender o que o cliente deseja ou necessita, 0 discernimento e a observação. U ma série de aspectos inerentes à alimentação do cliente deve ser observada no intento de que os alimentos ingeridos possam cumprir suas finalidades nutricionais: se os clientes estão se alimentando devidamente em qual idade e quantidade, se 0 al imento está de acordo com as necessidades específicas dos clientes e, se o processo de mastigação está adequado, dentre outros aspectos. É necessário também que se identifique o grau de dependência do cliente no intuito de ajudá-lo nas suas necessidades.

O s cuidados relativos à administração de medicamentos foi outro destaque da fala dos sujeitos, tanto no que diz respeito ao procedimento em si, quanto ao horário das medicações:

0 cuidado é ter cuidado na hora de fazer as coisas... A plicar uma injeção! [ ...] E sobre o remédio, édar no horário certo, direito (C3).

Saber ser profissional ao lidar com prazos e prescrições. [ ...] E ntão o cor po de enfermagem tem que cumprir os horários! (C14).

A administração de medicamentos é uma das funções assistenciais exercidas pela equipe de enfermagem em decorrência da prescrição médica.
É implementada na maior parte das instituições de saúde brasileir as por técnicos e auxiliares de enfermagem sob a supervisão de enfermeiras(7). E mbora não seja a responsável pela prescrição medicamentosa, a enfermeira deve conhecer as peculiaridades de todas as suas etapas, com a finalidade de prevenir erros que possam colocar em risco a vida do cliente, desde a indicação, ação, efeitos adver sos das substâncias, a técnica de administração e as intervenções necessárias diante de al guma inter corrência. I sso inclui os cuidados necessários à manutenção dos horários na sua administração. Assim, a enfermeira deve proceder de maneira responsável e ética para evitar possíveis iatrogenias.

A verificação da pressão arterial e da temperatura corpórea também esteve presente nas enunciações discursivas dos clientes sobre o cuidado:

Ahh! Toda vez que eu preciso verificar a pressão, a temperatura... Vocês vêm eestendem a mão! [ ...] (C10).

As mãozinhas são aquelas que trabalham! Que medem a pressão [ ...] (C11).

E sses cuidados for am articulados à importância das mãos de quem presta o cuidado para a realização dos mesmos, ou seja, trata-se de cuidados técnicos aliados a expressividade da enfermeira. Chamou a atenção também na fala dos clientes 0 fato de estarem atentos aos cuidados relacionados à biossegurança:

[ ...] lavar sempre as mãos... [ ...] N o caso das unhas, pra não passar bactérias... (C21).

P rimeiro eu citei o recolhimento do lixo como se fosse a limpeza. T odo o recolhimento de lixo hospitalar. P orque qualquer coisinha que caia no chão, a enfermeira que tem que chamar a menina do serviço, né? Colocar 0 lixo nos seus devidos lugares... (C24).

N essa figura aqui [ referindo-seao seu Almanaque], os enfer mei ros têm que usar essa roupa para se cuidar... [ ...] T ambém a máscara deve ser usada [ ...] (C8).

A equipe de enfer magem está constantemente exposta a uma diversidade de materiais e lixos, especial menteos biológicos. $\mathrm{D}$ ada à vulner abilidade dos profissionais de enfermagem a riscos ocupacionais, se deve adotar medidas adequadas de proteção individual e coletiva, como lavagem e antissepsia das mãos, uso de luva, máscara e jaleco; 
bem como 0 acondicionamento adequado de materiais utilizados e do lixo, a fim de não comprometer a biossegurança( ${ }^{(8)}$.

Outros cuidados recorrentes nas falas dos sujeitos for am os relativos a situações de emergência nas quais requerem atenção redobrada com 0 cliente e ações que englobam agilidade e eficiência. Dentre os cuidados de emergência, a massagem foi o de maior destaque:

[ ...] aqui [ referindo-se ao seu Almanaque] elevai iniciar uma massagem no coração (C7).

Além desses cuidados procedimentais, a observação ou inspeção também teve lugar no discurso dos sujeitos. T rata-se de um cuidado propedêutico de essencial importância para a enfermagem, sendo componente chave de sua organização:

[ ...] E elas têm aquele cuidado com eles e durante 0 período ficam observando o curativo, os aparelhos. [ ...]. E stão sempre perguntando como que estou! (C2).

Quando o paciente chama... A enfermeira tem que vir, ver 0 que está acontecendo! [ ...] (C9).

Para realizar mos a inspeção é necessária a utilização do sentido da visão, não só em relação aos segmentos corporais, como também aos aparelhos conectados aos clientes e ao ambiente físico ${ }^{(9)}$. Associada à observação está a habilidade na comunicação. E ssa habilidade resulta em uma observação mais apurada, pois colabora com que os clientes expressem o que estão sentindo. Eles assumem desse modo posição de sujeitos ativos no processo de cuidar:

Tem que estar ao lado dele, sempre presente O rientar como tem que ser direitinho! (C8).

Vocês orientam a gente a comer frutas elegumes. E vitar as comidas que faz em mal (C16).

[ ...] E o enfermeiro ajuda, vai explicando essas coisinhas! E o enfermeiro explica, mostra [ ...] (C17).

D enota-se nessas falas que a ação educativa da enfermeira não se restringe aos espaços extrahospitalares. A prática de educação em saúde é uma função precípua da enfermeira, cuja finalidade é a de promover um cuidado capaz de influenciar o estado de saúde do cliente de maneira positiva, mo- dificando juntamente com ele, hábitos que possam representar riscos à sua saúde.

\section{Dimensão expressiva do cuidado de enfermagem}

Para os clientes, os cuidados de enfermagem devem se expressar pela demonstração de carinho, atenção, zelo, amor, paciência. Segundo eles, esses elementos ajudam na recuperação do estado de saúde do cliente, por sua vez, aceleram a sua al ta hospitalar:

P rimeiramentea pessoa deveter amor à profissão! E sse éum cuidado básico! [ ...] Porquevai lidar com vida, com ser humano! E ntão tem que ter respeito! (C7).

E $m$ primeiro lugar, a gente tem que ter um bom coração e sentir muito amor pelo ser humano para poder tratar deles como eles tratam aqui, [ ...] . Tem todo 0 carinho, né? Senão não adianta ela [ a enfermeira] se formar! Se não tiver amor pelo outro ser, não adianta, né? (C11).

[ ... E E sse é um grande cuidado da enfermeira! N os tratar com carinho, com amor, com afeto (C24).

$\mathrm{Na}$ ótica de alguns clientes, 0 amor à profissão, ao ser humano e à prática de cuidar deve emergir como premissa básica nas ações de cuidado:

[ ...] T em... ] ustamenteo remédio, né? R emédio na hora certa... T ambém tem que ser feito com zelo e amor, éo mais importantel (C8).

Outras fal as referentes aos A Imanaques produzidos pel os sujeitos também revelaram sentimentos que imprimem expressividade no cuidar:

Primeiro eu coloquei [ referindo-se ao seu AImanaque] : M uito amor pelos pacientes. É pelo carinho que as enfer meiras têm, pelo cuidado que elas têm na hora de tirar agulha da gente, perguntando as coisas... [ ...] (C1).

E ntão... E u coloquei [ no A Imanaque] uma figura de afeto e carinho porque eu acho que ela representa os cuidados de enfer magem, né? [ ...] Tem que ter esse afeto, esse carinho pelo ser humano! (C5).

Cuidar abrange atenção, zel o e desvelo; é, pois, mais que um ato; uma atitude de ocupação, preocupação, de responsabilização e de envolvimento 
afetivo com o outro ${ }^{(10)}$. 0 cuidado fundamentase, portanto, em atitudes que revelam o amor para com 0 outro. T rata-se de uma relação que produz subjetividades expressas por diferentes sentimentos.

Quanto às diferentes formas de demonstrar esses sentimentos, chamou-nos à atenção o seu caráter lúdico. A produção artística dos sujeitos acerca do que pensam sobre o cuidado de enfermagem no contexto hospitalar revelou que este pode manifestar-se através do sorriso, do toque afetivo, do ol har empático, da conversa atenciosa. E sses elementos, de conteúdo lúdico, proporcionam efeitos terapêuticos positivos no cliente. A expressividade estética por parte da equipe de enfer magem culmina em sensações de al egria, prazer e mel hora de seu estado biopsicossocial(11). Proporciona assim, alter ações benéficas que auxiliam na restauração da saúde e bem-estar do cliente hospitalizado:

0 amor com que o profissional cuida da gente.. Que chega, que pergunta, quevêa gente triste evem conversar com a gente, que vem ver o porquê, conversar com carinho [ ...] (C1).

[ ...] quando a gente está no desesper o, quasena morte, a gente procura alguém pra nos ajudar a nos consolar. Aí a gente chega no hospital, a gente vai procurar uma enfermeira pra gente conversar, pra desabafar com ela (C6).

[ ...] a enfermagem équem auxilia na alimentação, dão atenção também conversando, ajudando no social epsicologicamente o paciente (C13).

0 discurso de $\mathrm{C} 1$ deixa clara a concepção de que 0 amor é o elemento gerador de atitudes expressivas. $\mathrm{C} 1$ e $\mathrm{C} 13$ apresentam em suas falas respectivamente a noção de que, no ato do cuidado, 0 carinho e a atenção são possibilitados pela conversa. N esse sentido, a conver sa emerge como el emento lúdico do cuidado. 0 cuidado de enfermagem se configura como um artifício para poder mos expressar 0 afeto que nos é inerente enquanto ser ${ }^{(12)}$. Há várias expressões no discurso de C 6 e C 13 que representam essa idéia: "ajuda a nos consolar"; "a gente vai ter esperança"; "ajuda social mente e psicologicamente o paciente".

A partir da relação estabelecida entre enfermeira-cliente através da expressão lúdica, houve 0 atendimento a algumas necessidades e desejos de C6 e $\mathrm{C} 13$ através da troca envolvente entre esses sujeitos. Vejamos nas falas a seguir o sorriso como forma de afetividade:

[ ...] 0 sor riso! A pessoa vem com um sor riso pra agradar, pra deixar o pacientemais alegre, mais feliz (C9).

[...] um profissional qualificado do qual um sorriso demonstra amor pelo o que faz e está sempre com um sorriso para com os pacientes e os demais colegas de trabalho [ referindo-se à sua produção artística em que escreveu a frase "bom ambiente de trabal ho"] (C12).

O sorriso é uma forma de comunicação com o outro que, através da sincronia dos músculos faciais manifesta sentimentos intrínsecos do ser. Para os clientes, a interação lúdica pelo sorriso é uma maneira de proporcionar ao indivíduo, co-partícipe do cuidado, mais alegria, felicidade e conforto. A T eoria do Cuidado $\mathrm{H}$ umano traz uma per spectiva ampliada do que seja conforto. T rata-se de um fator que atinge 0 ambiente externo e interno das pessoas. Para promovê-lo, é necessário um ambiente de cuidado onde se considerem os aspectos físicomental-sociocultural e espiritual ${ }^{(1)}$. 0 sorriso seria, portanto, segundo os clientes, uma forma de afetar o ambiente interno do indivíduo capaz de modificar o externo, gerando mudanças favoráveis à sua restauração. Sobre isso, vejamos o que revelou a produção dos AImanaques dos sujeitos:

[ ...] E ssa mão também representa o toque, que deixa a gente mais animada! D á um alívio na gente! Você enfrenta melhor a doença! (C11).

I sso! Porque aqui, até quando eu estou com dor, as enfermeiras "zoam" tanto que eu não sei se choro ou começo a rir! [ risos] E u acho legal! E quando eu estou muito triste, deprimida... Vocês vêm e estendem a mão de novo! Com brincadeiras, conversa, risadas... Assim! (C10).

[ ...] A qui eles vêem que estou chateada... ] á começam com piadinha, começo a rir... Aí já melhora tudo! Porque eu acho que enfermagem não é só você dar remédio (C10).

As brincadeiras são artifícios criativos utilizados pela enfer mag em para provocar descontração nos clientes hospitalizados, tendo em vista que 0 hospital se caracteriza como um ambiente frio, impessoal, local de tristeza e sofrimento ${ }^{(13)}$. A ssim, a ação criativa e sensível da enfer meira transforma 
0 ambiente do cuidar no hospital, possibilita o rompimento da seriedade exigida dos profissionais e viabiliza a restauração do cliente para um estado de bem-estar ${ }^{(11)}$.

No que tange ao toque como um cuidado expressivo, este possibilita troca de calor humano, 0 compartilhamento de mundos subjetivos distintos e singulares. 0 toque ameniza a dor, al ivia os sentimentos negativos, culminando num melhor enfrentamento da doença; promove conforto físico e psicológico. É, portanto, um componente do cuidado, eficaz na interação enfermeira-cliente. Aliase ao toque, a conversa e a escuta atentiva, concebida como uma maneira de demonstrar disponibilidade e inter esse em ouvir e perceber o outro. A apreensão e compreensão de sentimentos expressos nessa relação enfermeira-cliente contribuem de forma significativa para escape e alívio de tensões, al ém de favorecer maior aproximação da enfermeira com o cliente hospital izado.

E sses dados revel am que a afetividade no cuidado contribui de maneira ímpar no processo de restauração do cliente hospitalizado, consequentemente, favorece a um menor tempo de internação. N essa perspectiva, "o cuidado prestado por enfermeiro resulta em atitude mental positiva, movimento em direção a recuper ação e reabilitação, conforto físico, gratidão, reforço, dignidade e aceitação, confiança e satisfação"(14). U m exemplo que ilustra os efeitos positivos referenciados pel os sujeitos foi sua ação diante sentimentos de tristeza e melancolia, significados em suas falas, como depressão:

[ ...] U m sorriso amigo quando nós precisamos! Quantas vez es a gente está triste, está chateada e che ga per to da enfer meira e explica... E las procuram conversar e estar sempre sor rindo, pra ver sea gente passa por aquela depressão (C1).

[ ...] E a depressão, é porque elas conver sam muito com os pacientes, porquese o pacienteestiver depressivo, el as fazem por onde pra não ficar com depressão! (C2).

Os sujeitos destacaram a necessidade da conversa afetuosa entre enfer meir a e cliente, como elemento norteador para o equilíbrio emocional. Ela é capaz de promover a aproximação entre enfermeira e cliente. Transmite afeto, solidariedade e disposição em ajudar o outro, demonstrando interesse da enfermeira pelos sentimentos do cliente. A conversa é, portanto, um cuidado de enfermagem que se expressa ludicamente, trazendo segu- rança e bem-estar ao cliente, promovendo integração e apoio ao cliente no enfrentamento do processo de hospitalização e da própria doença ${ }^{(11)}$.

\section{CONSIDERAÇÕES FINAIS}

A partir da concepção dos clientes hospitalizados sobre o cuidado de enfermagem no hospital, foi possível caracterizar os cuidados de enfermagem como técnico-científicos e expressivos ${ }^{(1)}$. Esses cuidados foram concebidos como fundamentais pelos clientes, sujeitos da pesquisa, e devem estar articulados e se expressarem seguindo condutas éticas de responsabilidade, profissional ismo, zelo e respeito para com o cliente cuidado.

Quanto à valorização desses tipos de cuidado, ao falarem sobre o que pensavam acerca do cuidado de enfermagem, os clientes demonstraram seu entendimento quanto à aliança necessária entre a dimensão técnico-científica ea expressiva do cuidado; afinal, "uma complementa a outra"; sendo considerada como condições que permitem a efetividade no cuidar, acelerando, dessa forma, a alta hospitalar. E mbora valorizem um e outro tipo de cuidado, com mais ou menos intensidade, na dependência da situação requerida, os clientes conceber am o cuidado de enfermagem valor tanto técnico-científico, quanto expressivo. A lém disso, para que se sintam verdadeiramente cuidados, esperam que a enfermeira possa integrar ambos nas suas ações de cuidado. Seu conhecimento acerca das concepções dos clientes sobre o cuidado colabora na promoção de um ambiente que favoreça a sua restauração por meio da efetividade do cuidado, gerada nessa relação.

\section{REFERÊ NCIAS}

$1 \mathrm{~W}$ atson $\mathrm{J}$. Watson's theory of transper sonal caring. In: Wal hu PH, N euman B. Blueprint for use of nursing models: education, research, practice and administration. N ew York: N L M Press; 1996. p. 141-84.

2 F igueiredo PA 0 cuidado de enfer magem, na ótica de clientes hospital izados e sua relação com as tecnologias leves em saúde [ monografia]. R io de Janeiro: Escola de Enfermagem Anna N ery, U niversidade Federal do Rio de Janeiro; 2008.

3 M inistério da Saúde (BR ), Conselho N acional de Saúde, Comitê Nacional de Ética em Pesquisa em Seres H umanos. Resolução 196, de 10 de outubro de 1996: 
diretrizes e normas regulamentadoras de pesquisa envolvendo seres humanos. Brasília (D F); 1996.

4 Bardin L. Análise de conteúdo. Lisboa: E dições 70; 2004.

5 D omingues TAM , Chaves EC. $O$ conhecimento científico como valor no agir do enfermeiro. Rev Esc Enferm U SP. 2005;39(n esp):580-8.

6 Arruda E N, N unes A M P. Conforto em enfermagem: uma análiseteórico-conceitual. Texto Contexto E nferm. 1998;7(2):93-110.

7 Coimbra JAH, Cassiani SHB. Responsabilidade da enfermagem na administração de medicamentos: algumas reflexões para uma prática segura com qualidade de assistência. Rev Latino-A m Enfermagem. 2001;9(2):56-60.

8 Pinheiro J, Zeitoune RCG. H epatite B: conhecimento e medidas de biossegurança e a saúde do trabal hador de enfermagem. Esc A nna N ery Rev E nferm. 2008;12 (2):258-64.
9 Barros A L BL, organizadora. A namnese e exame físico: avaliação diagnóstica de enfermagem no adulto. Porto Alegre: Artmed; 2006.

10 Boff L. Saber cuidar: ética do humano, compaixão pela terra. 2ae ed. Petrópolis: Vozes; 1999.

11 Beuter M, Alvim NAT, M ostardeiro SCT S. 0 lazer na vida de acadêmicos de enfermagem no contexto do cuidado de si para o cuidado do outro. T exto Contexto Enferm. 2005;14(2):222-8.

12 Ferreira M A. A comunicação no cuidado: uma questão fundamental na enfermagem. Rev Bras E nferm. 2006;59(3):327-30

13 Batista M A. Presença do sagrado em um momento crítico: inter nação em uma U nidade de T erapia Intensiva. Rev Bras Enferm. 2004;57(5):579-85.

14 M aia ARC. Elementos e dimensões do cuidado na perspectiva de clientes ambulatoriais. T exto Contexto Enferm. 1998;7(2):133-50.

\section{E ndereço da autora / Dirección del autor /}

\section{Author's address:}

Paula A Ivarenga de $F$ igueiredo $M$ artins

Rua D r. Silvio Bastos T avares, 348, bloco 120, ap. 304

Cond. Resid. Recanto das Palmeiras, Parque Rodoviário 28051-250, Campos dos G oytacazes, RJ

E-mail:eaepaula@yahoo.com.br
Recebido em: 14/ 09/ 2009

A provado em: 15/ 03/2010 